\title{
The Role of Mucosal Defense in Intestinal Injury of Infants With Fetal Growth Retardation
}

\author{
Nushaba F. Panakhova, \\ ${ }^{1}$ Neonatology Department, Azerbaijan Medical University, Baku, Republic of Azerbaijan \\ *Corresponding author: Nushaba F. Panakhova, Neonatology Department, Azerbaijan Medical University, Baku, Republic of Azerbaijan. Tel:+99-4506324351, E-mail: nushaba2009@yandex.ru \\ Received 2015 January 23; Revised 2015 October 30; Accepted 2015 November 11.
}

\begin{abstract}
Background: Infants with fetal growth retardation (FGR) are prone to intestinal disorders.

Objectives: Aim of the study was to determine the role of mucosal defense ability in formation of gut injury in infants with FGR.

Materials and Methods: 44 premature infants who were admitted to the Neonatal Intensive Care Unit were divided into two groups: 20 infants with FGR (FGR group) and 24 appropriate-for-gestational age newborns (AGA group). Control group consisted of 22 premature infants who were delivered after uncomplicated pregnancy. Gut barrier function was evaluated by detecting serum intestinal trefoil factor (ITF) and intestinal fatty acid binding protein (IFABP). The level of serum IFABP and ITF was measured by using ELISA method.

Results: FGR group showed significantly higher ITF concentration than AGA group on the first days of life $(\mathrm{P}<0.01)$. High level of ITF in the FGR group significantly declines up to 7 th - 10th day of life $(\mathrm{P}<0.01)$. This reduction was accompanied by increase of IFABP which is a marker of ischemic intestinal mucosal injury. Correlation analyses showed that ITF had a negative correlation with IFABP.

Conclusions: Infants with fetal growth retardation are characterized by a high level of ITF on the first days of life. This protects intestinal mucosa under hypoxic conditions. Its subsequent decline accompanied by an increase of IFABP reflects the depletion of Goblet cells to secret ITF causing damage to the integrity of intestinal mucosal barrier.
\end{abstract}

Keywords: Perinatal Hypoxia, Fetal Growth Restriction, Intestinal Barrier, Mucosal Injury

\section{Background}

There is now ample evidence to suggest that fetal growth restriction (FGR) is strongly associated with increased perinatal mortality, neonatal morbidity, and in survivors, long term disability (1-3). The hemodynamic disturbances that occur in fetuses with growth retardation often persist after the birth and lead to increased vascular resistance in the descending aorta (4). The combination of fetal hypoxia and increased vascular resistance in mesenteric circulation can cause hypoxic-ischemic injury to the intestinal mucosa $(5,6)$.

Intestinal trefoil factor (ITF) is a structural component of the mucus layer and a member of the trefoil peptide family, which is essential for maintaining and recovering of the intestinal mucosal barrier (7). ITF also protects the epithelium of the intestinal mucosa against variety of noxious agents. This protective factor can stimulate not only cell migration and proliferation and promote epithelial cell repair, by interacting with intestinal mucin and increasing its viscosity is also able to interact with mucus and stabilize mucus gel. Although ITF is considered as an important self-protective mechanism of the intestine (8), its role in neonatal mucosal protection has not been thoroughly investigated. Due in part to failure of upregulation of ITF expression damaged mucosal regeneration may contrib- ute to the pathogenesis of necrotizing enterocolitis (NEC). Previous studies have demonstrated, in a hypoxia induced neonatal rat NEC model, ITF can decrease the contents of numerous inflammatory cytokines and enhance expression of anti-inflammatory cytokine, which alleviate the neonatal NEC and exert protective effects (9).

Intestinal fatty acid binding protein (IFABP) is a serological marker of mucosal injury (10). In experimental studies the level of circulating IFABP has been stated to correlate with the histological status of the epithelium after intestinal ischemia-reperfusion (11). In humans, IFABP levels are increased in clinical conditions with intestinal injury, including intestinal infarction, neonatal necrotizing enterocolitis and acute mesenteric ischemia (12). Moreover, it was found that elevated urinary IFABP predicts NEC within several days prior to clinical onset and serial IFABP measurements accurately predict development of complicated disease $(13,14)$.

\section{Objectives}

Aim of the study was to determine the role of mucosal defense ability in the formation of gut injury that might contribute to the pathophysiology of intestinal barrier dysfunction in infants with FGR.

Copyright (C) 2016, Growth \& Development Research Center. This is an open-access article distributed under the terms of the Creative Commons Attribution-NonCommercial 4.0 International License (http://creativecommons.org/licenses/by-nc/4.0/) which permits copy and redistribute the material just in noncommercial usages, provided the original work is properly cited. 


\section{Materials and Methods}

This study was conducted in accordance with the Declaration of Helsinki. After receiving complete information on the study's scope and its purposes, the parents of all of the infants involved in this study provided written consent for participation in it. All methods were carried out due to the guidelines of the Azerbaijan National Committee on Bioethics and Ethics of Science and Technology.

The study population included all singleton preterm newborns with a gestational age of 33 to 36 weeks that were consecutively admitted to the K. Farajova Pediatric Institute Neonatal Intensive Care Unit from January 2011 to November 2011. Exclusion criteria were major congenital anomalies including gastrointestinal tract, TORCH group infections and signs of genetic syndromes. To eliminate the influence of NEC on studied biochemical parameters, newborns with a proven and advanced stage of NEC were also excluded from the study. The NEC diagnosis definition was based on clinical findings consistent with Bell's staging, confirmed by radiologic evidence of NEC (15).

Estimation of the gestational age was carried out on date of the most recent menstrual period of the mother and an ultrasonogram, and was approved according to the scale by Ballard et al. (16). The diagnosis of FGR was defined in case of the evaluated fetal weight of less than the 10th percentile for gestational age, reduced amniotic fluid volume, Doppler ultrasound of the umbilical artery revealing absent end diastolic flow velocity, and also on serial obstetric ultrasonographic examination of fetal measurements showing diminished growth velocity (17).

Forty-four infants with a high risk of hypoxic ischemic encephalopathy born in 33 - 36 weeks of gestational age were recruited for this study. The study group infants were divided into two groups: 20 infants with fetal growth restriction (FGR group) and 24 appropriate-forgestational age newborns (AGA group). The control group consisted of 2 preterm neonates born at 33-36 weeks gestational age, who had 1-minute Apgar score of 7 or more, were delivered normally after uncomplicated pregnancy, presented no neurological symptoms, normal cranial ultrasounds and did not demand medication during the neonatal period.

All infants were closely monitored for gastric residuals, bilious aspirates and abdominal distension. Data about maternal age, parity, maternal preeclampsia, birth weight, gestational age, Apgar scores at 1 and 5 minutes, blood gases, type of feeding, and sign of feeding intolerance were included in each individual infant's chart.Neonatal death was defined as death within the first 28 days of life.

\subsection{Blood Collection}

Blood samples were collected in EDTA tubes, separated by centrifugation and kept under $-70^{\circ} \mathrm{C}$ until the testing was performed.

\subsection{Determination of IFABP and ITF in Peripheral Blood}

Serum IFABP was measured at room temperature by method enzyme-linked immunosorbent assay (Human IFABP-ELISA test kit, HyCult Biotechnology B.V, Uden, The Netherlands). This kit has a minimum detection level of $0.047 \mathrm{ng} / \mathrm{ml}$.

The serum ITF concentration was measured using a commercial sandwich enzyme-linked immunosorbent kit (Human TTF3 Ucsn Life Science İnc. USA) following the manufacturer's instructions. The minimum detectable dose of human ITF is typically less than $0.58 \mathrm{ng} / \mathrm{ml}$.

To avoid pseudopositive and pseudonegative ITF and IFABP, double-check test results were used. The concentrations of IFABP and ITF were determined on days 1 and 7 of extrauterine life.

\subsection{Statistical Analysis}

The data in all groups were tested for normality and found to have non-normal distributions. Differences among study groups were estimated with the MannWhitney U test. The Spearman rank-order correlation coefficient was applied for the calculation of correlations. Significance level was set at $\mathrm{P}<0.05$ for all analyses. Nominal variables such as gender, maternal preeclampsia, Cesarean section, and the gastrointestinal disorders were compared using Fisher's exact test.

\section{Results}

\subsection{Clinical Characteristics}

Except for preeclampsia, which was significantly higher in infants with FGR (Table 1), there were no differences in maternal characteristics among the study groups of infants. There were no significant differences between the FGR and AGA groups in mean gestational age, Apgar score and the number of neonatal deaths. However, significant differences ( $P<0.05$ ) were found for birth weight and the incidence of clinical signs of intestinal motility disturbances (bile stained, abdominal distension).

\subsection{Biochemical Markers}

As shown in Figure 1, mean values of ITF in the AGA group did not differ between the 1st and 7th day. Although the serum concentrations of IFABP on the 7th day of life were 2.4 times higher compared to the 1st day, this difference was not significant $(P>0.05)$. When the infants with FGR were compared with the AGA newborns in terms of ITF, the FGR group showed significantly higher ITF concentration on the 1st day $(\mathrm{P}<0.05)$. A high level of ITF in the FGR group significantly declined up to the 7th day of life $(P<0.05)$. In contrast, the low IFABP level in the FGR newborn group rose significantly up to the 7th day of life, compared with AGA group parameters $(\mathrm{P}<0.05)$. 
We also found a negative linear correlation between serum IFABP and ITF concentration on day 7 of life in the studied groups, but this correlation was significant only in the FGR infant group $(r=-0.74, \mathrm{P}<0.05$ in FGR; $r=-0.24, \mathrm{P}>0.05$ in AGA) (Figure 2). A non-statistically reliable relationship was determined between these parameters on the 1st day ( $r=0.21$ in FGR; $r=0.16$ in AGA) (data not shown).

\begin{tabular}{|c|c|c|}
\hline & FGR Group $(\mathbf{n}=\mathbf{2 0})$ & $\operatorname{AGA}$ Group $(n=24)$ \\
\hline Median birth weight, $\mathrm{g}$ & $1456.3(1000-1800)^{b}$ & $2108.3(1700-2500)$ \\
\hline Gestational age, wk & $35(33-36)$ & $35.4(33-36)$ \\
\hline Maternal age, $y$ & $27.3(21-31)$ & $30.5(23-28)$ \\
\hline Parity, primigravida & $12(60)$ & $13(54.2)$ \\
\hline Cesarean section & $5(25)$ & $5(20.8)$ \\
\hline Maternal preeclampsia & $10(50)^{b}$ & $4(16.7)$ \\
\hline Maternal chronic hypertension & $5(25)$ & $3(12.5)$ \\
\hline Oligohydramnios & $8(40)$ & $2(8.3)$ \\
\hline Gender, male & $9(45)$ & $11(45.8)$ \\
\hline \multicolumn{3}{|l|}{ Apgar scores } \\
\hline 1st min & $4.4(4-5)$ & $5.3(4-6)$ \\
\hline 2nd min & $6.1(5-7)$ & $6,1(5-6)$ \\
\hline Intraventricular hemorrhage & $7(35)$ & $6(25)$ \\
\hline Apnea & $4(20)$ & $3(12.5)$ \\
\hline Abdominal distention & $6(30)^{b}$ & $1(4.2)$ \\
\hline Gastric residual & $5(25)$ & $6(25)$ \\
\hline Bile-stained & $6(30)^{b}$ & $1(4.2)$ \\
\hline Death & $1(5)$ & - \\
\hline TPN & $8(40)^{b}$ & $3(12.5)$ \\
\hline Breast milk feeding & $6(30)$ & $9(37.5)$ \\
\hline Probiotic intake & $12(60)$ & $15(62.5)$ \\
\hline
\end{tabular}

${ }^{\mathrm{a}}$ The data are shown as mean range or No. (\%).

$\mathrm{b}_{\mathrm{P}}<0,05$-compared with AGA group.

A

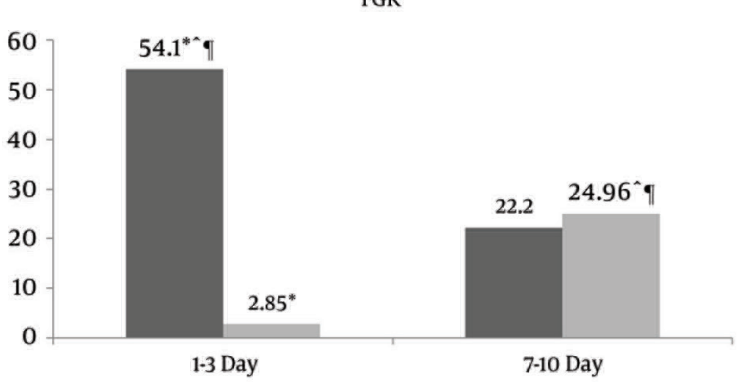

\section{C}

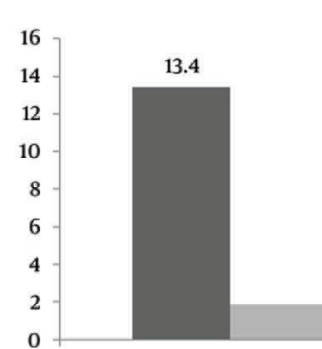

1-3 Day
B

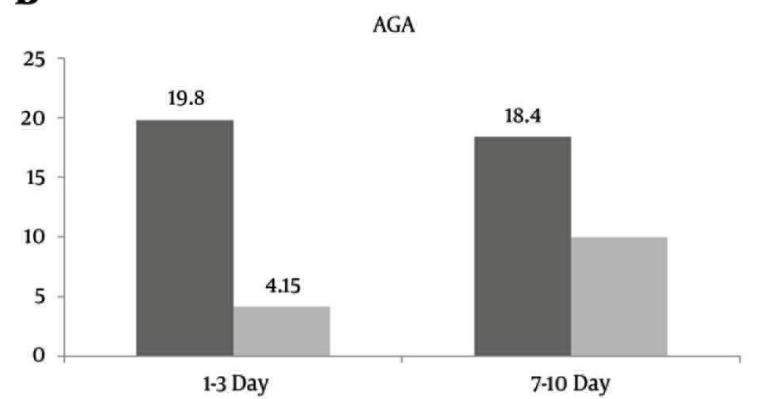

Control

Figure 1. The Level of Biochemical Markers in Study Groups 
A

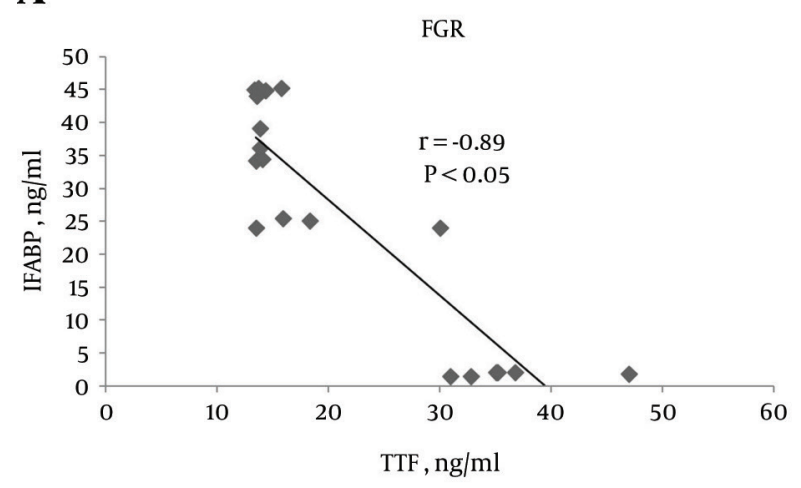

B

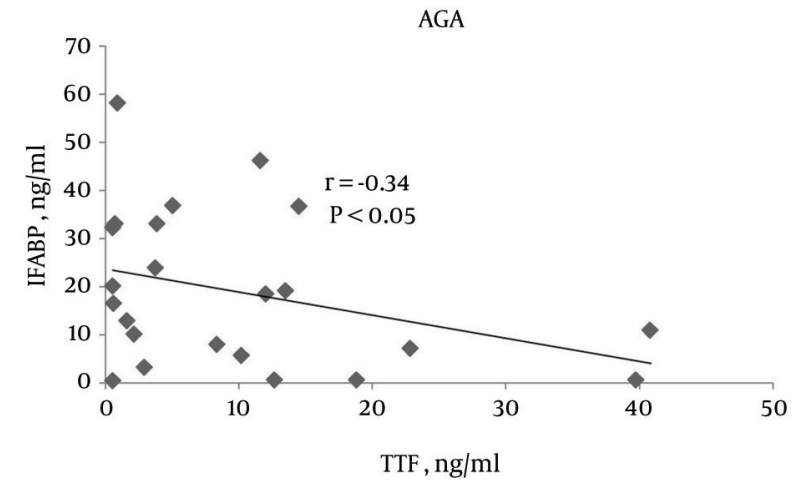

Figure 2. Spearman Rank Correlation Between Serum IFABP and ITF Concentrations in Study Groups

\section{Discussion}

FGR may initiate alterations in the developmental pattern of the intestinal barrier and may be responsible for FGR-associated increased morbidity. The intestine of FGR neonates is characterized by reduced weight (proportionate to body weight), length, wall thickness, crypt depth and villous height $(18,19)$. In neonates with FGR abdominal problems with delayed meconium passage, bilious vomiting, abdominal distension and a delay in tolerating enteral feeding are frequently observed within the first days of life. These disorders may happen as a result of persistent postnatal redistribution of regional blood flow, result in gastrointestinal problems and may negatively affect gut motility (20). In accordance with our hypothesis, colonic mucosal barrier alteration may be responsible for intestinal frailty in newborns with fetal growth retardation.

During this study we established that infants with FGR are characterized by a high level of serum ITF on the first days of life. In contrast, other investigations show the lack of mucin and ITF expression in the colon of rats with FGR that may contribute to the frailty of the intestinal barrier associated with FGR (21). Tian et al. also found low levels of ITF in premature and asphyxiated infants
(22). However, Furuta et al. demonstrated that hypoxia induces the epithelial specific, barrier-protective protein intestinal ITF through an HIF-l $\alpha$-dependent mechanism (23). Similarly, it is known that HIF-la overexpression also leads to intrauterine growth retardation (24). These results suggest that the high concentration of this protein in the 1st day of life in growth-restricted infants is aimed at maintaining the mucus barrier under hypoxic conditions. At first it was thought that the high ITF concentration in children with FGR would compensate for damage to the intestine, and intestinal dysfunction development would be observed in these infants because the ITF level increases according to long-term chronic intrauterine hypoxia, and high ITF concentration appears as a protective mechanism of intestinal injury.

However, the decreased level of ITF on day 7 of life in the FGR group was accompanied by a significant increase in IFABP serum concentration, which points to an intestinal mucosal injury. Showing the relationship between transient mucosal ischemia and epithelial damage measured with tonometry and IFABP, respectively, Mensink et al. demonstrated that IFABP is an early marker of mucosal ischemia (25). The high level of IFABP found in the FGR group in our research suggests that these infants have impaired mucosal perfusion, which may be due to persistent intestinal blood flow disturbances. Maruyama et al. demonstrated that the resistance index and relative vascular resistance in the superior mesenteric artery tend to be higher in the small for gestational age group than in the appropriate for gestational age group, and although intestinal blood flow velocity in FGR infants increases after birth, it is lower than in the AGA infants during the early neonatal period (26). In our research, a steep decrease in the level of ITF in infants with FGR during the first week of life may be due to inadequate intestinal blood flow. This theory is supported by the negative correlation between IFABP and ITF serum level. Ikeda et al. established that during the kinetic analysis of goblet cell dynamics of the small intestine in restitution, goblet cells may play an important role in restitution after an ischemic reperfusion injury, but under ischemic conditions these cells could not provide protective function (27). Similarly, Varga et al. also detected during intestinal ischemia a decrease in the numbers of goblet cells responsible for synthesis of trefoil factor peptides (28). In spite of declining ITF in the FGR group, the ITF level was higher than that in the control group, which points to continuing intestinal inflammatory processes.

In conclusion, infants with FGR have a high level of ITF, which is important to the maintenance and repair of the intestinal mucosal barrier in the first days of life. However, the subsequent decline of intestinal mucosa in secretion of ITF is associated with injury to the mucosal-barrier, as evidenced by the higher level of IFABP. Clinically these changes have been accompanied by signs of intestinal motility disturbances. Thus, continuing ischemia and hypoxia in FGR infants is the cause of exhaustion of com- 
pensatory protective mechanisms of the mucus layer and may predispose such infants to the development of NEC.

\section{Acknowledgments}

The authors sincerely thank the Science Development Foundation under the President of the Azerbaijan Republic for supporting the research.

\section{References}

1. Bernstein IM, Horbar JD, Badger GJ, Ohlsson A, Golan A. Morbidity and mortality among very-low-birth-weight neonates with intrauterine growth restriction. The Vermont Oxford Network. Am J Obstet Gynecol. 2000;182(1 Pt 1):198-206. [PubMed: 10649179]

2. Garite TJ, Clark R, Thorp JA. Intrauterine growth restriction increases morbidity and mortality among premature neonates. Am JObstet Gynecol. 2004;191(2):481-7. doi:10.1016/j.ajog.2004.01.036. [PubMed:15343225]

3. Paulusova E, Stillova L, Haskova K, Matasova K. Splanchnic Circulation in Small for Date Newborns. Acta Medica Martiniana. 2012;12(3):5-10.

4. Korszun P, Dubiel M, Breborowicz G, Danska A, Gudmundsson S Fetal superior mesenteric artery blood flow velocimetry in normal and high-risk pregnancy. J Perinat Med. 2002;30(3):235-41. doi:10.1515/JPM.2002.033. [PubMed:12122906]

5. Robel-Tillig E, Vogtmann C, Bennek J. Prenatal hemodynamic disturbances - pathophysiological background of intestinal motility disturbances in small for gestational age infants. Eur J Pediatr Surg. 2002;12(3):175-9. doi:10.1055/s-2002-32723. [PubMed: 12101499]

6. Turner JR. Intestinal mucosal barrier function in health and disease. Nat Rev Immunol. 2009;9(11):799-809. doi: 10.1038/nri2653. [PubMed:19855405]

7. Kim YS, Ho SB. Intestinal goblet cells and mucins in health and disease: recent insights and progress. Curr Gastroenterol Rep. 2010;12(5):319-30. doi: 10.1007/s11894-010-0131-2. [PubMed: 20703838]

8. Emami S, Le Floch N, Bruyneel E, Thim L, May F, Westley B, et al. Induction of scattering and cellular invasion by trefoil peptides in src- and RhoA-transformed kidney and colonic epithelial cells. FASEB J. 2001;15(2):351-61. doi: 10.1096/fj.00-0355com. [PubMed: 11156951]

9. Shi L, Zhou PH, Xi JL, Yu HG, Zhang BH. Recombinant human trefoil factor 3 ameliorates bowel injury: its anti-inflammatory effect on experimental necrotizing enterocolitis. Int J Pept. 2014;2014:634135. doi: 10.1155/2014/634135. [PubMed: 24688551]

10. van Wijck K, Lenaerts K, Grootjans J, Wijnands KA, Poeze M, van Loon LJ, et al. Physiology and pathophysiology of splanchnic hypoperfusion and intestinal injury during exercise: strategies for evaluation and prevention. Am J Physiol Gastrointest Liver Physiol. 2012;303(2):G155-68. doi: 10.1152/ajpgi.00066.2012. [PubMed: 22517770]

11. Kanda T, Nakatomi Y, Ishikawa H, Hitomi M, Matsubara Y, Ono T, et al. Intestinal fatty acid-binding protein as a sensitive marker of intestinal ischemia. Dig Dis Sci. 1992;37(9):1362-7. [PubMed: 1505286]

12. Guthmann F, Borchers T, Wolfrum C, Wustrack T, Bartholomaus $\mathrm{S}$, Spener F. Plasma concentration of intestinal- and liver-FABP in neonates suffering from necrotizing enterocolitis and in healthy preterm neonates. Mol Cell Biochem. 2002;239(1-2):22734. [PubMed: 12479590]

13. Gregory KE, Winston AB, Yamamoto HS, Dawood HY, Fashemi T, Fichorova RN, et al. Urinary intestinal fatty acid binding protein predicts necrotizing enterocolitis. J Pediatr. 2014;164(6):1486-8. doi:10.1016/j.jpeds.2014.01.057. [PubMed: 24636854]

14. Schurink M, Kooi EM, Hulzebos CV, Kox RG, Groen H, Heineman E, et al. Intestinal fatty acid-binding protein as a diagnostic marker for complicated and uncomplicated necrotizing enterocolitis: a prospective cohort study. PLoS One. 2015;10(3):e0121336. doi: 10.1371/journal.pone.0121336. [PubMed: 25793701]

15. Gordon PV, Swanson JR, Attridge JT, Clark R. Emerging trends in acquired neonatal intestinal disease: is it time to abandon Bell's criteria? J Perinatol. 2007;27(11):661-71. doi: 10.1038/sj.jp.7211782. [PubMed:17611610]

16. Ballard JL, Khoury JC, Wedig K, Wang L, Eilers-Walsman BL, Lipp R. New Ballard Score, expanded to include extremely premature infants. J Pediatr. 1991;119(3):417-23. [PubMed:1880657]

17. Harkness UF, Mari G. Diagnosis and management of intrauterine growth restriction. Clin Perinatol. 2004;31(4):743-64. doi: 10.1016/j.clp.2004.06.006. [PubMed:15519426]

18. D'Inca R, Kloareg M, Gras-Le Guen C, Le Huerou-Luron I. Intrauterine growth restriction modifies the developmental pattern of intestinal structure, transcriptomic profile, and bacterial colonization in neonatal pigs. J Nutr. 2010;140(5):925-31. doi: 10.3945/jn.109.116822. [PubMed: 20335628]

19. Baserga M, Bertolotto C, Maclennan NK, Hsu JL, Pham T, Laksana GS, et al. Uteroplacental insufficiency decreases small intestine growth and alters apoptotic homeostasis in term intrauterine growth retarded rats. Early Hum Dev. 2004;79(2):93-105. doi: 10.1016/j.earlhumdev.2004.04.015. [PubMed:15324990]

20. Robel-Tillig E, Vogtmann C, Faber R. Postnatal intestinal disturbances in small-for-gestational-age premature infants after prenatal haemodynamic disturbances. Acta Paediatr. 2000;89(3):324-30. [PubMed:10772281]

21. Fanca-Berthon P, Michel C, Pagniez A, Rival M, Van Seuningen I, Darmaun D, et al. Intrauterine growth restriction alters postnatal colonic barrier maturation in rats. Pediatr Res. 2009;66(1):4752. doi:10.1203/PDR.0b013e3181a2047e. [PubMed:19287349]

22. Tian LY, YI LZ, Zhang J. Factors affecting the level of intestinal trefoil factor (ITF) in meconium of newborns. Chinese J Birth Health Heredity. 2011;1:75-7.

23. Furuta GT, Turner JR, Taylor CT, Hershberg RM, Comerford K, Narravula $\mathrm{S}$, et al. Hypoxia-inducible factor 1-dependent induction of intestinal trefoil factor protects barrier function during hypoxia. J Exp Med. 2001;193(9):1027-34. [PubMed:11342587]

24. Tal R, Shaish A, Barshack I, Polak-Charcon S, Afek A, Volkov A, et al. Effects of hypoxia-inducible factor-1alpha overexpression in pregnant mice: possible implications for preeclampsia and intrauterine growth restriction. Am J Pathol. 2010;177(6):2950-62. doi:10.2353/ajpath.2010.090800. [PubMed: 20952590]

25. Mensink PB, Hol L, Borghuis-Koertshuis N, Geelkerken RH, Huisman AB, Doelman CJ, et al. Transient postprandial ischemia is associated with increased intestinal fatty acid binding protein in patients with chronic gastrointestinal ischemia. EurJ Gastroenterol Hepatol. 2009;21(3):278-82. doi:10.1097/MEG.0b013e32832183a7. [PubMed:19279473]

26. Maruyama K, Koizumi T. Superior mesenteric artery blood flow velocity in small for gestational age infants of very low birth weight during the early neonatal period. J Perinat Med. 2001;29(1):64-70. doi:10.1515/JPM.2001.009. [PubMed:11234619]

27. Ikeda H, Yang CL, Tong J, Nishimaki H, Masuda K, Takeo T, et al. Rat small intestinal goblet cell kinetics in the process of restitution of surface epithelium subjected to ischemia-reperfusion injury. Dig Dis Sci. 2002;47(3):590-601. [PubMed:11911348]

28. Varga J, Toth Jr S, Toth S, Tomeckova V, Gregova K, Vesela J. The relationship between morphology and disaccharidase activity in ischemia- reperfusion injured intestine. Acta Biochim Pol. 2012;59(4):631-8. [PubMed: 23198280] 